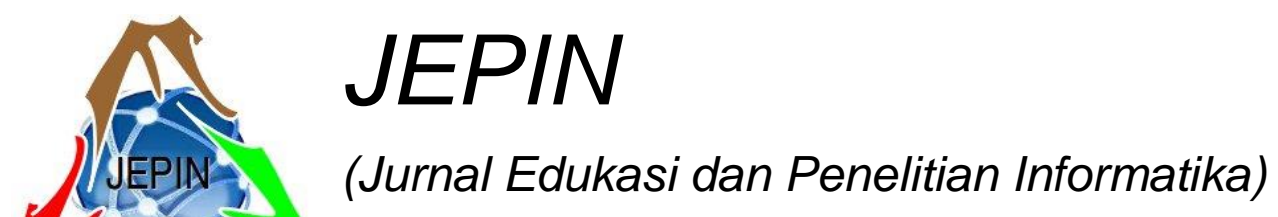

\title{
Variasi Thresholding untuk Segmentasi Pembuluh Darah Citra Retina
}

\author{
Anita Desiani ${ }^{\# 1}$, Des Alwine Zayanti ${ }^{\# 2}$, Rifkie Primartha ${ }^{\# 3}$, Filda Efriliyanti ${ }^{\# 4}$, Nur Avisa Calista Andriani ${ }^{\# ~}$ \\ ${ }^{\#}$ Universitas Sriwijaya \\ Jl. Masjid Al Gazali, Bukit Lama, Kec. Ilir Bar. I, Kota Palembang, Sumatera Selatan 30128 \\ lanita_desiani@unsri.ac.id \\ ${ }^{2}$ desalwinezeunsri.ac.id \\ 3rifkiedilkom.unsri.ac.id \\ ${ }^{4}$ fildaefriliyanti99@gmail.com \\ ${ }^{5}$ nuravisacalistaandriani@gmail.com
}

\begin{abstract}
Abstrak - Segmentasi pembuluh darah pada retina diperlukan pada deteksi dini penyakit Diabetic Retinopathy pada citra retina. Penelitian ini menggunakan tiga tahapan yaitu pre-processing, segmentasi dan post-processing yang akan membandingkan hasil dari 3 metode segmentasi yang menggunakan nilai Thresholding yaitu Adaptive Thresholding, Binary Thresholding, dan Otsu Thresholding. Hasil pengujian terhadap tiga metode yang digunakan menunjukan bahwa metode Binary Thresholding mendapat rata-rata akurasi, sensitivitas dan spesifisitas tertinggi yaitu 95\%, $58 \%, 98 \%$. Untuk Adaptive Thresholding mendapat rata-rata akurasi sebesar $91 \%$, sensitivitas $36 \%$, spesititiftas $97 \%$. Dan metode Otsu Thresholding mendapatkan rata-rata akurasi $86 \%$, sensitivitas $22 \%$, dan spesifisitas $90 \%$. Dari hasil ketiga metode ini dapat dilihat akurasi yang dihasilkan oleh metode Thresholding sudah sangat baik dalam melakukan segmentasi citra, tetapi nilai sensitivitas dari masing-masing metode Thresholding masih rendah. Hal ini dapat disimpulkan metode Thresholding masih sulit mendapatkan lebih banyak fitur pembuluh darah pada citra retina.
\end{abstract}

Kata kunci - Segmentasi, Citra, Pembuluh Darah, Retina, Thresholding

\section{Pendahuluan}

Adanya perubahan pada mata dapat menandakan seseorang sedang mengalami suatu gangguan penyakit[1]. Beberapa bentuk perubahan pada mata yang disebabkan oleh suatu gangguan diantaranya adalah pembesaran pembuluh darah. Selain itu munculnya cabang-cabang tak normal pada mata. Salah satu gangguan yang ada adalah Diabetic Retinopathy (DR). DR merupakan salah satu gangguan penyakit yang menyerang pembuluh darah pada retina[2]. Deteksi dini dapat memberikan penanggulangan awal supaya dampaknya tidak parah pada retina. Deteksi dini pada juga dapat mencegah hilangnya penglihatan[3]. Kebutuhan citra untuk medis memerlukan teknik dan kamera khusus, demikian juga kebutuhan waktu dan kepakaraan khusus untuk menganalisis citra tersebut. keterbatasan pakar dan waktu yang cukup lama dapat menjadi kendala dalam pealayanan kesehatan pasien[4]. Dalam hal ini bantuan komputer sangat diperlukan. Pemanfaatan bidang komputer seperti pembelajaran mesin sangat berkembang luas di dunia kesehatan salah satunya bidang segmentasi citra untuk membantu mendapatkan fitur tertentu untuk medeteksi suatu gangguan penyakit.

Segmentasi merupakan teknik untuk memisahkan fitur tertentu dari fitur lain yang tidak dibutuhkan pada citra. Fitur yang dibutuhkan menjadi foreground pada citra dan fitur lain menjadi background. Tujuan dari segmentasi adalah mendapatkan fitur khusus pada citra tertentu sesuai dengan kebutuhan terhadap suatu citra. Maka dari itu, segmentasi diperlukan dalam proses pengambilan fitur. Hasil segmentasi sangat mempengaruhi hasil deteksi pola suatu gangguan penyakit sehingga perlu suatu metode yang mampu memberikan hasil segmentasi yang baik dan akurat. Deteksi gangguan DR dilakukan berdasarkan gangguan yang terjadi pada pembuluh darah retina. Segmentasi pada citra retina untuk penderita gangguan DR hanya membutuhkan bagian pembuluh darah retina yang menjadi foreground sedangkan fitur lain seperti kornea dan lain-lain menjadi background citra.

Berbagai metode segmentasi dikembangkan. Namun hasil segmentasi juga dipengaruhi oleh kualitas citra seperti kontras yang tidak seimbang dan banyaknya noise yang dikandung. Citra dengan kualitas rendah dapat menurunkan hasil dari segmentasi. Pada proses segmentasi diperlukan juga tahapan perbaikan kualitas citra karena kualitas citra yang baik memberikan hasil segmentasi yang baik juga. Salah satu metode yang digunakan adalah metode Thresholding. Metode Thersholding adalah metode yang digunakan untuk segmentasi gambar didasarkan pada derajat keabuan sebuah citra. Hasil segmentasi dari metode tersebut berupa citra biner ditandai sebagai foreground dengan warna putih atau disimbolkan dengan 1 jika nilai pada piksel lebih besar dari nilai ambang (threshold), dan menjadi background (warna hitam atau 0) jika sebaliknya. Nilai ambang pada 
Thersholding dapat diambil sebagai nilai lokal atau global [5].

Beberapa metode Thresholding diantaranya adalah metode pertama yaitu Adaptive Thresholding. Metode ini mampu menghubungkan representasi tekstur dan detektor ciri yang optimal. Metode ini juga digunakan untuk mengurangi ciri yang tidak dibutuhkan dalam citra retina. Metode yang kedua adalah Binary Thresholding. Metode ketiga menggunakan Otsu Thresholding atau dikenal juga sebagai Thresholding Global. Penelitian [6] menggunakan Otsu Thresholding berbasis wilayah. Hasil penelitian menunjukan nilai rata-rata akurasi dan spesifisitas yang tinggi yaitu $95,33 \%$ dan $97,14 \%$, namun nilai sensitivitas untuk kedua dataset masih tergolong kecil yaitu $75.21 \%$.

Analisis pada proses segmentasi harus dikerjakan untuk menentukan metode mana yang memberikan hasil yang akurat. Hasil yang akurat memberikan hasil yang baik dalam proses klasifikasi terutama pada citra retina agar tidak terjadi kesalahan pada diagnosa penyakit yang dialami oleh seseorang. Penelitian ini membandingkan kinerja dari ketiga metode yang menggunakan nilai Thresholding yaitu Adaptive Thresholding, Binary Thresholding dan Otsu Thresholding pada segmentasi pembuluh darah retina dengan menggabungkan tahapan perbaikan citra untuk pre-processing dan post-processing pada tahap setelah segmentasi untuk dapat mengetahui metode mana yang memberikan kinerja terbaik. Hasil penelitian ini dapat diketahui mana metode yang dapat memberikan hasi segmentasi yang paling akurat sehingga dapat digunakan untuk mengklasifikasikan jenis penyakit pada retina mata.

\section{Metode PENELITIAN}

Pada metode penelitian terdapat lima bagian atau tahapan yang dilakukan yaitu:

\section{A. Input Citra}

Penelitian ini menggunakan dataset Digital Retinal Images for Vessel Extraction (DRIVE) dan dataset Structured Analysis of the Retina (STARE). Kedua dataset tersebut adalah dataset yang banyak digunakan pada berbagai penelitian dan dapat diakses secara gratis. Ukuran dimensi citra dataset DRIVE yaitu $565 \times 584$ piksel menggunakan format .tif. Dataset lainnya adalah STARE. STARE merupakan citra retina yang berwarna yang diperoleh dari kamera fundus pada penelitian di Belanda, dimana ada 397 subjek citra retina dengan format .ppm. Penggunaan dataset STARE diharapkan dapat mempermudah diagnosis penyakit yang ada pada mata manusia, dengan melihat bentuk pupil mata, serat optik dan pembuluh darah retina[7]. Ukuran dimensi citra dataset STARE yaitu $605 \times 700$ piksel.

\section{B. Pre-processing}

Tahap ini digunakan untuk memperbaiki kualitas citra digital yang digunakan. Proses awal dilakukan dengan mengambil green channel pada citra retina dengan tujuan mendapatkan hasil pembuluh darah yang lebih jelas. Jika dibandingkan dengan red channel dan blue channel hasil green channel menghasilkan citra yang paling baik, maka green channel dipilih digunakan dalam proses ini [5]. Setelah itu dilakukan pengubahan piksel warna menjadi Grayscale. Grayscale memiliki rentang gradisasi warna hitam dan putih yang sangat cocok digunkan untuk pengelohan gambar. Kemudian dilakukan proses perbaikan kualitas kontras citra dengan Contrast Limited Adaptive Histogram Equalization (CLAHE).

Metode CLAHE digunakan untuk memperolerh sebaran nilai abu-abu. CLAHE diharapkan menampilkan fitur yang tersembunyi dengan menerapkan pemerataan histogram untuk tiap-tiap nilai piksel. CLAHE memberikan nilai batas maksimal tinggi sebuah histogram dinamakan clip limit yang akan membagi citra menjadi beberapa bagian kecil dengan ukuran identik sehingga histogram dari gambar luaran sesuai dengan histogram yang ditunjukkan oleh parameter ditribusi [2], [5], [8]. Perhitungan clip limit mengunakan persamaan (1):

$$
\begin{aligned}
& \beta=\frac{K}{L}\left(1+\frac{\alpha}{100}\left(S_{\max }-1\right)\right) \\
& \text { dengan : } \\
& \mathrm{K}=\text { Luas ukuran daerah } \\
& \mathrm{L}=\text { Range kabu-abuan }(1-256) \\
& \alpha=\text { Clip factor , dengan limit } 0-100
\end{aligned}
$$

Selain menggunakan CLAHE juga diterapkan Gamma Correction untuk meningkatkan kembali kontras citra. Gamma Correction adalah nama operasi nonlinear yang digunakan untuk mengkodekan dan mendekode nilai $l u$ minance atau tristimulus dalam video atau sistem gambar $\operatorname{diam}[9]$.

Untuk menghilangkan noise dan mempertajam pembuluh darah pada citra retina digunakan denoising dengan menggunakan Non Local Means (NLM). NLM berfungsi untuk menghilangkan noise dengan mempertahankan fitur citra penting seperti tepi, dan pembuluh darah halus. Filter NLM menggunakan asumsi bahwa citra mengandung sejumlah besar kemiripan diri dari citra asli untuk menentukkan bobot piksel sehingga dapat melakukan penyaringan noise.

Proses selanjutnya yaitu mendeteksi tepi citra dengan Detect Ridges. Detect Ridges mendeteksi garis tipis yang lebih gelap atau lebih terang dari lingkungan citra yang diinputkan dengan mengikuti pendekatan geometris yang berbeda, dan mendefinisikan terang (gelap) titik ridges sebagai titik yang diasumsikan kecerahan maksimum (minimum) dalam arah arah kurva utama. Setelah itu proses filterisasi dengan menggunakan Median blur, Gaussian Filter, Gaussian Bluring, 2D-Gabor Filter dan Transformasi Bottom Hat.

Operasi Median blur dilakukan dengan memeriksa setiap piksel secara berurutan, jika nilai piksel lebih besar dari nilai rata-rata dalam mask, maka nilai bahwa piksel tersebut terkontaminasi oleh nilai dan ganti dengan nilai median dari mask. Jika tidak maka dapat dipertahankan dengan nilai asli piksel [10]. Gaussian Filter merupakan filter linier dimana nilai pembobotannya diberikan oleh 
fungsi Gaussian. Sebaran pada noise diasumsikan mengikuti sebaran Gaussian atau sering disebut dengan Zero Mean [11]. Zero Mean pada fungsi gaussian diberikan pada persamaan (2):

$$
g(x, y)=e^{\frac{\left(x^{2}+y^{2}\right)}{2 \sigma^{2}}}
$$

dimana $x$ merupakan jarak titik awal pada sumbu horizontal sedangkan $y$ adalah jarak titik awal pada sumbu vertikal, dan $\sigma$ adalah nilai standard deviasi.

Selain Gaussian Filter juga terdapat Gaussian blur. Teknik ini bertujuan untuk menghaluskan citra retina yang masih mengandung banyak noise di dalamnya. Proses Gaussian blur ini menghasilkan citra untuk menentukan potensi gradien pada citra. Gradien sendiri merupakan operator yang digunakan untuk mendeteksi edge atau tepi. Proses Gaussian blur mempunyai persamaan sebagai berikut[12]:

$$
G(x, y)=\frac{1}{2 \pi \sigma^{2}} e^{-\frac{x^{2}+y^{2}}{2 \sigma^{2}}}
$$

dimana $\sigma$ adalah standar deviasi pada distribusi Gaussian. Persamaan (3) digunakan agar permukaan yang diperoleh adalah permukaan yang mengikuti distribusi Gauss. Nilai distribusi tersebut nantinya digunakan untuk membentuk konvolusi matriks yang akan diterapkan pada citra asli.

2D-Gabor Filter merupakan fungsi linear yang digunakan untuk mendeteksi tepi dalam pemrosesan citra. Pada penerapannya Gabor Filter digunakan untuk menangkap informasi frekuensi tinggi, dan dipilih respon maksimum dalam setiap piksel [13]. 2D-Gabor Filter dibentuk dari dua komponen yaitu fungsi gaussian pada frekuensi serta orientasi tertentu dan gelombang sinusoidal dalam bentuk kompleks (dengan lengkungan). Metode 2D-Gabor Filter mampu menghubungkan representasi tekstur dan detektor ciri yang optimal. 2DGabor filter berfungsi meminimalisasi ciri yang tidak penting didalam citra retina. 2D-Gabor Filter terdapat dari sebuah fungsi gaussian yang dimodulasi dengan menggunakan variasi frekuensi ditunjukkan sebagai berikut[14]:

$$
G(x, y)=\exp \left\{-\frac{1}{2}\left(\frac{x_{12}}{\sigma_{x^{2}}}+\frac{y_{1^{2}}}{\sigma_{y^{2}}}\right)\right\} \cos 2 \pi x_{1} f
$$

dengan nilai $x_{1}=x \cos \theta-y \sin \theta$ dan nilai $y_{1}=$ $x \sin \theta+y \cos \theta, x$ dan $y$ merupakan nilai koordinat piksel dalam citra, $f$ merupakan frekuensi gelombang Sinusoidal, $\theta$ merupakan kontrol terhadap orientasi dari sebuah fungsi $2 D$-Gabor Filter, dan $\sigma$ merupakan standar deviasi dimana $\sigma_{x}=\sigma_{y}$. Penerapan 2D-Gabor Filter pada citra dilakukan menggunakan 12 rotasi arah yang berbeda dengan interval rotasi sebesar $15^{\circ}$, sehingga akan didapatkan 12 template dari masing-masing filter yang kemudian akan dicari maksimal respon untuk mendapatkan hasil ekstraksi pembuluh darah retina yang optimal [13]. Pencarian maksimal respon dilakukan dengan membandingkan 12 pola kemudian dipilih template yang memiliki warna paling hitam. Hasil ekstraksi pembuluh darah berupa citra yang sudah dapat dibedakan antara pembuluh darah retina dan background [15], [16].

Transfromasi Bottom Hat digunakan untuk menghilangkan objek gelap dengan background terang. Persamaan dari transformasi ini dapat dilihat pada persamaan (5) berikuti [17]:

$$
A_{b o t}=(A \odot B)-\mathrm{A}
$$

dimana dengan A adalah citra asli, B merupakan structuring element berupa matriks dengan operator yang merupakan garis, bangun, piringan, bentuk diamond, dan lainlain. Operasi Closing, dan $A_{\text {bot }}$ merupakan citra hasil Transformasi Bottom Hat.

\section{Segmentasi}

Segmentasi dapat diartikan sebagai teknik atau cara yang biasa digunakan untuk mengambil fitur sehingga mendapatkan pola pada daerah yang mempunyai kemiripan yang bertujuan untuk memisahkan fitur atau obyek lain selain pembuluh darah menjadi background. Metode segementasi yang digunakan dalam penelitian ini yaitu Adaptive thresholding, Binary Thresholding, dan Otsu thresholding. Dalam pengolahan citra, Thresholding biasanya digunakan untuk segmentasi citra. Dalam Thresholding setiap nilai piksel citra dibandingan nilai ambang (threshold) terntu. Pada citra abu-abu teknik Thresholding digunakan untuk membuat citra biner [18]. Proses binarisasi citra didefinisikan sesuai dengan persamaan 6 [5], [19].

$$
G(x, y)= \begin{cases}1, & f(x, y)>T \\ 0, & f(x, y) \leq T\end{cases}
$$

dengan T adalah nilai ambang batas, $f(x, y)$ adalah fungsi pasaangan koordinat piksel pada citra, $G(x, y)$ adalah titik koordinat piksel pada citra biner. Jika nilai suatu piksel lebih besar dari nilai ambang batas, maka bisa dianggap sebagai pembuluh darah, namun jika nilai suatu piksel kurang dari nilai ambang batas, maka akan dianggap sebagai background. Teknik Thresholding diklasifikasi-kan menjadi dua yaitu global dan lokal.

Salah satu teknik Thresholding Gobal yang sering digunakan untuk segmentasi adalah Otsu Thresholding. Metode Otsu Thresholding mencari ambang batas yang meminimalkan varians antar kelas dari gambar yang tersegmentasi. Ambang batas (threshold) global seperti pada Otsu Thresholding dapat diketahui dengan mencari seluruh rentang nilai piksel gambar sampai varians antar kelas mencapai minimum [20]. Sedangkan teknik Thresholding Lokal yang digunakan pada penelitian ini yaitu Adaptive Thresholdling. Penentuan nilai ambang batas dari Adaptive Thresholdling yaitu dihitung untuk setiap piksel, berdasarkan beberapa dari statistik lokal seperti range, dan ragam dari piksel tetangga [20]. 


\section{Post-processing}

Tahap ini digunakan untuk memperhalus, menajamkan, dan memperbaikan kualitas dari hasil proses segmentasi. Metode yang digunakan dalam tahap ini yaitu operasi morfologi Opening dan Closing. Operasi Opening digunakan untuk membuat kontur gambar lebih jelas, halus, dan mengurangi noise haasil segmentasi [21]. Operasi Opening secara sederhana dilakukan dengan Operasi Erosi diikuti oleh Dilatasi. Operasi Opening didefinisikan oleh persamaan berikut [17]:

$$
A \circ B=(A \ominus B) \oplus B
$$

dimana

$$
\begin{aligned}
& A \oplus B=\left\{x \mid(B)_{x} \cap A \neq \phi\right\} \\
& A \ominus B=\left\{x \mid(B)_{x} \cap A^{c} \neq \phi\right\}
\end{aligned}
$$

dengan A adalah citra asli B merupakan structuring element yang berupa matriks operator yang berbentuk line shape, disk, diamond, dan sebagaianya. $\bigoplus$ adalah Operasi Dilasi, $\Theta$ adalah Operasi Erosi, dan o adalah Operasi Opening.

Operasi Closing berguna untuk menghaluskan fitur dengan menyambungkan piksel-piksel yang dekat serta menghilangkan lubang-lubang kecil yang ada di tengah citra. Langkah kerja operasi ini dilakukan dengan cara operasi dilasi terlebih dahulu kemudian diiukti erosi. Persamaan (10) berikut adalah persamaan closing [17]:

$$
A \odot B=(A \oplus B) \ominus B
$$

dimana $\bullet$ adalah Operasi Closing.

\section{E. Analisis Hasil}

Hasil yang diperoleh dari tahapan tersebut kemudian akan dibandingkan satu dengan ground truth dari masingmasing citra pada dataset untuk dapat menilai sejauh mana kinerja dari masing-masing metode. Beberapa ukuran yang sering digunakan dalam mengukur kinerja dari metode klasifikasi adalah akurasi, senstifitas dan spesifisitas[22]. Pada tahapan ini kinerja dari setiap metode akan diukur berdasarkan nilai akurasi, sensitivitas dan spesifisitas dengan menggunakan Confusion Matrix[22].

\section{HASIL DAN PEMBAHASAN}

\section{A. Segmentasi dengan Metode Adaptive Thresholding}

Data yang digunakan pada metode ini adalah dataset STARE dengan contoh gambar yaitu “im0162". Pada tahap pre-processing dilakukan, citra retina terlebih dahulu di konversi dari BGR ke RGB pada Gambar 1.a. Proses selanjutnya dilakukan ekstraksi green channel, red channel dan blue channel dari ketiga channel tersbut terlihat hasil dari grenn channel memberikan hasil paling baik, Hasil green channel dapat dilihat pada Gambar 1.b. Selanjutnya citra retina diubah menjadi Grayscale. Setelah itu dilakukan peningkatan kontras yang dibarengi juga dengan penggunaan CLAHE agar nilai yang berlebih pada citra retina dapat diatasi yang dapat dilihat pada Gambar 1.c

Setelah itu dilakukan deteksi pembuluh darah dengan $2 D$-Gabor Filter pada citra retina setelah citra retina su- dah melalui tahapan pre-processing CLAHE yang dapet diliat pada Gambar 1.d. Kemudian digunakan Gaussian Blur untuk menguraing noise pada citra retina. Selanjutnya barulah masuk ke proses segmentasi dengan menggunakan metode Adaptive Thresholding. Dilanjukan dengan post-processing yaitu Operasi Opening dan Closing yang berfungsi menghilangkan garis tepi. Contoh hasil segmentasi pada Adaptive Thresholding dapat dilihat di Gambar 1.e. Beberapa citra hasil proses segmentasi menggunakan Adaptive Thresholding dapat dilihat pada Tabel 1 .

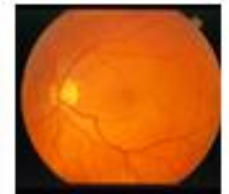

a.

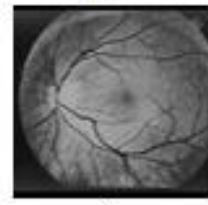

d.

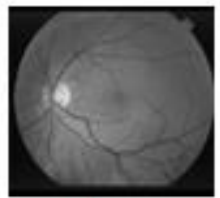

b.

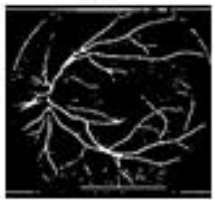

e.
Gambar. 1. a. Citra RGB b. Green channel c. CLAHE d. 2D-Gabor Filter e. Adaptive Thresholding

TABEL I

Perbandingan Hasil SEgmentasi Pembuliuh Darah Citra Retina DENGAN METODE ADAPTIVE THRESHOLDING

\begin{tabular}{|l|l|l|l|}
\hline $\begin{array}{l}\text { Nama } \\
\text { File }\end{array}$ & $\begin{array}{l}\text { Cround } \\
\text { Truth }\end{array}$ & Hasil \\
\hline $\operatorname{im} 0001$ & & \\
\hline $\operatorname{im} 0002$ & & \\
\hline $\operatorname{im} 0004$ & &
\end{tabular}

\section{B. Segmentasi dengan Metode Binary Thresholding}

Data yang digunakan pada metode ini adalah dataset DRIVE dengan contoh gambar yaitu "02_test". Pada tahap pre-processing dilakukan dengan memilih green channel pada citra retina yang dapat dilihat pada Gambar 2.b. Pemilihan green channel dilakukan karena memiliki kontras gambar terbaikbaik dibandingkan dengan red channel dan blue channel. Setelah itu dilakukan perbaikan 
kontras gambar menggunakan metode CLAHE yang dapat dilihat pada Gambar 2.c dan Gamma Correction pada Gambar 2.d. Namun citra yang dihasilkan masih mengandung noise yang dapat mengganggu perhitung hasil dari proses segmentasi. Oleh karena itu digunakan metode denoising untuk menghilangkan noise pada Gambar 2.e. Selanjutnya dengan menggunakan Detect Ridges untuk medeteksi pembuluh darah yang tipis yang (Gambar 2.f dan 2.g). Proses berikutnya digunakan Median Blur pada Gambar 2.h untuk menghaluskan gambar dan mempertahankan gambar hasil pre-processing. Langkah terakhir dilakukan segmentasi menggunakan Binary Thresholding (Gambar 2.I). Hasil segmentasi pembuluh darah retina menggunakan Binary Thresholding dengan dataset DRIVE dapat dilihat pada Tabel 2.

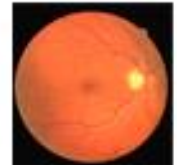

a.

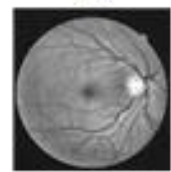

e.

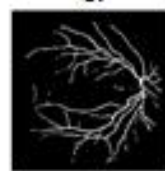

i.

Gambar 2. a. Citra RGB b. Green channel c. CLAHE d. Gamma Correction e. Denoised f. Detected ridges g. Detectd ridgres h. Median Blur i. Binary Thresholding.

TABEL II

PERbandingan Hasil SEgmentasi PEMbuliuh DaRAH CitRa ReTina DENGAN METODE BINARY THRESHOLDING

\begin{tabular}{|l|l|l|l|}
\hline $\begin{array}{l}\text { Nama } \\
\text { File }\end{array}$ & $\begin{array}{l}\text { Cround } \\
\text { Truth }\end{array}$ & Hasil \\
\hline 01_test & & \\
\hline 03_test & & \\
\hline 08_test & & \\
\hline 14 test & & \\
\hline
\end{tabular}

\section{Segmentas dengan Metode Otsu Thresholding}

Data yang digunakan pada metode ini yaitu STARE dengan contoh gambar yaitu "im0044". Tahap pertama adalah menyiapkan gambar fundus retina sebagai input image Tahapan kedua dilakukan adalah melakukan Grayscale pada citra retina. Proses tersebut digunakan agar dapat mengurangi dimensi citra dan mengubahnya dari mode warna RGB menjadi mode keabuan (0-255) sebagai tahap awal untuk memudahkan pendeteksian optic disk retina. Tahapan ketiga yang dilakukan adalah preprocessing untuk memperbaiki kontras citra yang rendah dengan menggunakan metode CLAHE dan penghalusan citra pada gambar dengan Gaussian Blur yang dapat dilihat pada Gambar 3.a. Tahapan kelima adalah Transformasi Bottom Hat yang digunakan untuk menghilangkan lingkaran luar yang ada di retina yang dapat dilihat pada Gambar 3.b. Dan tahapan berikutnya adalah segmentasi yang menggunakan Otsu Thresholding yang dapat dilihat pada Gambar 3.c. Untuk tahapan post-processing dilakukan Operasi Opening pada Gambar 3.d. dan Closing pada Gambar 3.e. Beberapa citra hasil segmentasi menggunakan Otsu Thresholding dapat dilihat pada Tabel 3.

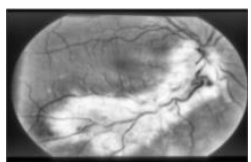

a.

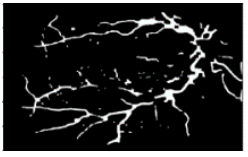

d.

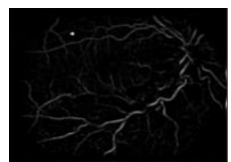

b.

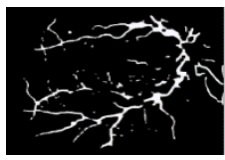

e.

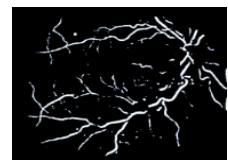

c.
Gambar. 3. a. Gaussian Blurring b.Transformasi Bottom Hat c. Otsu Thresholding d. Opening e. Closing

TABEL III

PERBANDingan HASIL SEgMENTASI PEMBUliUH DARAH CITRA RETINA DENGAN METODE OTSU THRESHOLDING

\begin{tabular}{|l|l|l|l|}
\hline $\begin{array}{l}\text { Nama } \\
\text { File }\end{array}$ & Citra & Ground Truth & Hasil \\
\hline $\mathrm{im0077}$ & & & \\
\hline $\mathrm{im0082}$ & & &
\end{tabular}




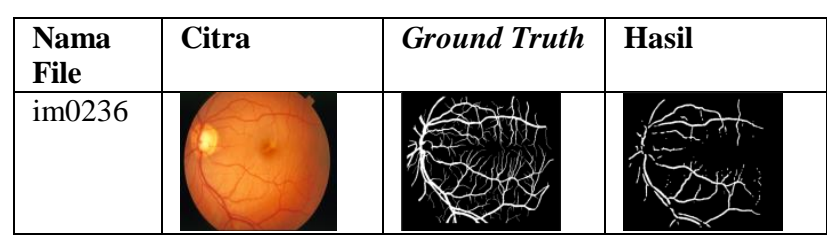

D. Analisi Hasil Perfoma Metode Segmentasi dengan Metode Segmententasi Thresholding

Dari beberapa hasil segmentasi pada Tabel I, II, dan III diukur kinerja metode segmentasi yang digunakan dengan menggunakan Confusion Matrix seperti akurasi sensitivitas dan spesifisitas. Hasil pengukuran akurasi, sensitivitas dan spesifisitas dapat dilihat pada Tabel IV, dan V dengan membandingkan foreground dan background dari gambar segmentasi dengan ground truth pada dataset.

TABEL IV

HASIL PERFORMA METODE BINARY THRESHOLDING PEMBULUH DARAH CITRA RETINA

\begin{tabular}{|c|c|c|c|}
\hline \multirow{2}{*}{$\begin{array}{c}\text { Citra } \\
\text { Retina }\end{array}$} & \multicolumn{3}{|c|}{ Binary Thresholding (\%) } \\
\hline & $\begin{array}{c}\text { Akurasi } \\
\text { (Acc) }\end{array}$ & $\begin{array}{c}\text { Sensitivitas } \\
\text { (Sen) }\end{array}$ & $\begin{array}{c}\text { Spesifisitas } \\
\text { (Spe) }\end{array}$ \\
\hline 01test & 95 & 57 & 99 \\
\hline 02test & 95 & 53 & 00 \\
\hline 03test & 95 & 63 & 99 \\
\hline 04test & 94 & 42 & 99 \\
\hline 05test & 93 & 33 & 100 \\
\hline 06test & 94 & 39 & 99 \\
\hline 07test & 95 & 50 & 99 \\
\hline 08test & 94 & 40 & 99 \\
\hline 09test & 95 & 57 & 99 \\
\hline 10test & 93 & 85 & 93 \\
\hline 11 tets & 92 & 78 & 94 \\
\hline 12test & 93 & 85 & 94 \\
\hline 13test & 95 & 57 & 99 \\
\hline 14 test & 96 & 59 & 99 \\
\hline 15 test & 96 & 62 & 99 \\
\hline 16test & 95 & 74 & 97 \\
\hline 17 test & 93 & 22 & 100 \\
\hline 18test & 96 & 68 & 98 \\
\hline 19test & 96 & 55 & 99 \\
\hline 20test & 96 & 77 & 97 \\
\hline
\end{tabular}

Berdasarkan Tabel IV dan V diperoleh hasil dari proses segmentasi memberikan kinerja akurasi, sensitivitas, dan spesifisitas yang berbeda-beda. Jika dalam proses segmentasi didapatkan citra yang bentuk pembuluh darahnya semakin kompleks maka sulit mendeteksi fiturfitur yang diperlukan. Jika metode segmentasi kesulitan dalam mendeteksi fitur tersebut maka akurasi yang diperoleh rendah dibandingkan proses segmentasi pada citra dengan pola pembuluh darah yang sederhana. Hasil segmenasi menunjukkan kemampuan setiap metode dalam melakukan segmentasi pembuluh darah pada masingmasing citra retina.

TABEL V

PERBANDINGAN HASIL PERFORMA METODE ADAPTIVE THRESHOLDING DAN OTSU THRESHOLDING PEMBULUH DaRAH CITRA RETINA

\begin{tabular}{|c|c|c|c|c|c|c|}
\hline \multirow{2}{*}{$\begin{array}{c}\text { Citra } \\
\text { Retina }\end{array}$} & \multicolumn{3}{|c|}{$\begin{array}{c}\text { Adaptive } \\
\text { Thresholding }\end{array}$} & \multicolumn{3}{c|}{$\begin{array}{c}\text { Otsu } \\
\text { Thresholding }\end{array}$} \\
\cline { 2 - 7 } & Acc & Sen & Spe & Acc & Sen & Spe \\
\hline im0001 & 0.92 & 0.38 & 0.98 & 0.84 & 0.13 & 0.91 \\
\hline im0002 & 0.94 & 0.31 & 0.97 & 0.90 & 0.06 & 0.94 \\
\hline im0003 & 0.92 & 0.52 & 0.94 & 0.88 & 0.09 & 0.94 \\
\hline im0004 & 0.91 & 0.15 & 0.97 & 0.88 & 0.09 & 0.93 \\
\hline im0005 & 0.90 & 0.44 & 0.96 & 0.86 & 0.15 & 0.90 \\
\hline im0044 & 0.90 & 0.29 & 0.98 & 0.93 & 0.85 & 0.93 \\
\hline im0077 & 0.91 & 0.41 & 0.98 & 0.85 & 0.16 & 0.87 \\
\hline im0081 & 0.90 & 0.36 & 0.98 & 0.82 & 0.20 & 0.87 \\
\hline im0082 & 0.91 & 0.41 & 0.98 & 0.85 & 0.15 & 0.88 \\
\hline im0139 & 0.87 & 0.42 & 0.95 & 0.90 & 0.83 & 0.91 \\
\hline Im0162 & 0.91 & 0.44 & 0.97 & 0.83 & 0.15 & 0.89 \\
\hline im0163 & 0.93 & 0.50 & 0.98 & 0.86 & 0.17 & 0.89 \\
\hline im0235 & 0.89 & 0.29 & 0.99 & 0.83 & 0.21 & 0.86 \\
\hline im0236 & 0.90 & 0.31 & 0.99 & 0.84 & 0.26 & 0.87 \\
\hline im0239 & 0.90 & 0.35 & 0.98 & 0.83 & 0.17 & 0.88 \\
\hline im0240 & 0.87 & 0.26 & 0.98 & 0.80 & 0.17 & 0.85 \\
\hline im0255 & 0.90 & 0.48 & 0.96 & 0.83 & 0.21 & 0.88 \\
\hline im0291 & 0.93 & 0.31 & 0.97 & 0.90 & 0.09 & 0.94 \\
\hline im0319 & 0.94 & 0.27 & 0.99 & 0.90 & 0.09 & 0.94 \\
\hline im0324 & 0.90 & 0.23 & 0.98 & 0.88 & 0.15 & 0.90 \\
\hline
\end{tabular}

Nilai rata-rata akurasi untuk metode Adaptive Thresholding sebesar $91 \%$, sedangkan rata-rata akurasi metode Otsu Thresholding lebih kecil yaitu hanya $86 \%$. Sedangan untuk metode Binary Thresholding diperoleh rata-rata akurasi paling tinggi yaitu 95\%. Pada metode Binary Thresholding diperoleh rata-rata sensitivitas yang paling tinggi yaitu $58 \%$, sedangkan rata-rata sensitivitas yang paling kecil yaitu sebesar $22 \%$ menggunakan metode Otsu Thresholding. Untuk metode Adaptive Thresholding hanya memperoleh rata-rata sensitivitas sebesar 36\%. Ratarata spesifisitas untuk ketiga metode sudah tinggi yaitu metode Adaptive Thresholding 97\%, Binary Thresholding 98\%, dan Otsu Thresholding 90\%.

Dari Tabel VI dapat dilihat bahwa [5] menggunakan metode yang mengkombinasikan perbaikan citra menggunakan Principal Component Analysis (PCA) dan CLAHE dengan segmentasi pembuluh darah menggunakan metode Otsu Thersholding menghasilkan nilai akurasi sangat baik namun nilai spesifisitas yang rendah. 
Pada penelitian [16] menggunakan 2D-Gabor Filter dan metode optimasi Imperialism Competitive Algorithm (ICA) dengan diterapkan pada dataset DRIVE diperoleh rata-rata akurasi yang tinggi yaitu 95,3\%. Namun dalam penelitian ini tidak ada perhitungan sensitivitas dan spesifisitas. Pada penelitian [6] menggunakan CLAHE untuk meningkat kontras citra dan Filter Morfologi untuk menghilangkan noise objek. Kemudian dilakukan segmentasi pembuluh darah dengan menggunakan pendekatan Morfologi Hessian dan Otsu Thresholding berbasis wilayah. Hasil penelitian menunjukan nilai rata-rata akurasi dan spesifisitas yang tinggi yaitu $95,33 \%$ dan $97,14 \%$. Nilai sensitivitas pada penelitian ini masih harus ditingkatkan lagi agar dapat mendeteksi pembuluh darah retina yang lebih banyak terutama pembuluh darah yang halus dan tipis.

TABEL VI

Perbandingan Hasil Penelitian Sebelumnya untuk Segmentasi PEMBULUH DARAH CitRa RETINA

\begin{tabular}{|c|c|c|c|}
\hline \multirow{2}{*}{ Metode } & \multicolumn{3}{|c|}{ Hasil (\%) } \\
\cline { 2 - 4 } & Acc & Sen & Spe \\
\hline$[16]$ & 95,3 & - & - \\
\hline$[5]$ & 95.6 & 72,3 & 97.4 \\
\hline$[6]$ & 95,33 & 75,21 & $97,14$. \\
\hline $\begin{array}{c}\text { Metode yang diusulkan } \\
\text { (Adaptive Thresholding) }\end{array}$ & 91 & 36 & 97 \\
\hline $\begin{array}{c}\text { Metode yang diusulkan } \\
\text { (Binary Thresholding) }\end{array}$ & 95 & 58 & 98 \\
\hline $\begin{array}{c}\text { Metode yang diusulkan } \\
\text { (Otsu Thresholding) }\end{array}$ & 86 & 22 & 90 \\
\hline
\end{tabular}

\section{KESIMPULAN}

Berdasarkan hasil dari metode yang diusulkan, diperoleh metode Binary Thresholding yang memiliki performa paling baik yaitu berdasarkan rata-rata akurasi dan spesifisitas yang tinggi yaitu 95\%, 58\%, 98\%. Hasil ini memiliki arti metode ini memberikan hasil paling baik dalam melakukan segmentasi pembuluh darah citra retina dengan baik sesuai dengan tahapan yang dilakukan, yaitu dengan perbaikan kulitas citra, reduksi noise, dan postprocessing setelah segementasi. Rata-rata hasil performa untuk spesifisitas dari ketiga metode Thresholding sangat tinggi diatas $90 \%$. Sayangnya ketiga metode Thresholding ini masih menghasilkan nilai sensitivitas rendah di bawah. Hal ini menunjukan metode Thresholding masing-masing masih kesulitan dalam mendeteksi pembuluh darah yang tipis dan dengan percabangan yang kompleks.

\section{UCAPAN TERIMA KASIH / ACKNOWLEDGMENT}

Penelitian/Publikasi ini dibiayai pada : Anggaran Dipa Badan-Layanan-Umum Universitas SriwijayaTahun Anggaran 2021 Nomor SP DIPA 023.17.2.677515/2021, tanggal 23 November 2020 Sesuai dengan SK Rektor 007/UN.9/SK.LP@M.PT/2021

\section{REFERENSI}

[1] T. Sabhanayagam, V. Prasanna Venkatesan, and K. Senthamaraikannan, "A Comprehensive Survey on Various
Biometric Systems," International Journal of Applied Engineering Research, vol. 13, no. 5, pp. 2276-2297, 2018

[2] H. E. Moss, "Retinal Vascular Changes are a Marker for Cerebral Vascular Diseases," Current Neurology and Neuroscience Reports, vol. 15, no. 7, pp. 1-9, 2015, doi: 10.1007/s11910-0150561-1.

[3] U. T. V. Nguyen, A. Bhuiyan, L. A. F. Park, and K. Ramamohanarao, "An effective retinal blood vessel segmentation method using multi-scale line detection," Pattern Recognition, vol. 46, no. 3, pp. 703-715, 2013, doi: 10.1016/j.patcog.2012.08.009.

[4] R. C. Wihandika and N. Suciati, "Retinal Blood Vessel Segmentation with Optic Disc Pixels Exclusion," I.J. Image, Graphics and Signal Processing, vol. 7, no. June, pp. 26-33, 2013 , doi: 10.5815/ijigsp.2013.07.04.

[5] J. Dash and N. Bhoi, "Retinal blood vessel segmentation using Otsu thresholding with principal component analysis," Proceedings of the 2nd International Conference on Inventive Systems and Control, ICISC 2018, no. Icisc, pp. 933-937, 2018, doi: 10.1109/ ICISC.2018.8398938.

[6] K. BahadarKhan, A. A. Khaliq, and M. Shahid, "A morphological hessian based approach for retinal blood vessels segmentation and denoising using region based otsu thresholding," PLOS ONE, vol. 11, no. 7, pp. 1-19, 2016, doi: 10.1371/journal.pone.0158996.

[7] L. Câmara Neto, G. L. B. Ramalho, J. F. S. Rocha Neto, R. M. S. Veras, and F. N. S. Medeiros, "An unsupervised coarse-to-fine algorithm for blood vessel segmentation in fundus images," Expert Systems with Applications, vol. 78, pp. 182-192, 2017, doi 10.1016/j.eswa.2017.02.015.

[8] R. P. Singh and M. Dixit, "Histogram Equalization: A Strong Technique for Image Enhancement," International Journal of Signal Processing, Image Processing and Pattern Recognition, vol. 8, no. 8, pp. 345-352, 2015, doi: 10.14257/ijsip.2015.8.8.35.

[9] C. Shi, Y. Wang, B. Xiao, and C. Wang, "OTSU guided adaptive binarization of CAPTCHA image using gamma correction," Proceedings - International Conference on Pattern Recognition, vol. 0, pp. 3962-3967, 2016, doi: 10.1109/ICPR.2016.7900253.

[10] Y. Zhu and C. Huang, "An Improved Median Filtering Algorithm for Image Noise Reduction," Physics Procedia, vol. 25, pp. 609616, 2012, doi: 10.1016/j.phpro.2012.03.133.

[11] N. P. Singh, R. Kumar, and R. Srivastava, "Local entropy thresholding based fast retinal vessels segmentation by modifying matched filter," in International Conference on Computing, Communication and Automation, ICCCA 2015, 2015, pp. 11661170, doi: 10.1109/CCAA.2015.7148552.

[12] J. Flusser, S. Farokhi, C. Höschl, T. Suk, B. Zitová, and M. Pedone, "Recognition of Images Degraded by Gaussian Blur," IEEE Transactions on Image Processing, vol. 25, no. 2, pp. 790 806, 2016, doi: 10.1109/TIP.2015.2512108.

[13] S. Pathan, P. C. Siddalingaswamy, and K. G. Prabhu, "A pixel processing approach for retinal vessel extraction using modified Gabor functions," Progress in Artificial Intelligence, vol. 7, no. 1, pp. 1-14, 2018, doi: 10.1007/s13748-017-0134-4.

[14] Y. Zhang, W. Li, L. Zhang, X. Ning, L. Sun, and Y. Lu, "Adaptive Learning Gabor Filter for Finger-Vein Recognition," IEEE Access, vol. 7, pp. 159821-159830, 2019, doi: 10.1109/ACCESS. 2019.2950698.

[15] F. Farokhian and H. Demirel, "Blood vessels detection and segmentation in retina using Gabor filters," 2013 High Capacity Optical Networks and Emerging/Enabling Technologies, HONETCNS 2013, pp. 104-108, 2013, doi: 10.1109/HONET.2013.6729766.

[16] F. Farokhian, C. Yang, H. Demirel, S. Wu, and I. Beheshti, "Automatic parameters selection of Gabor filters with the imperialism competitive algorithm with application to retinal vessel segmentation," Biocybernetics and Biomedical Engineering, vol. 37, no. 1, pp. 246-254, 2017, doi: 10.1016/j.bbe.2016.12.007.

[17] R. Kushol, M. H. Kabir, M. S. Salekin, and A. B. M. Ashikur Rahman, "Contrast enhancement by top-hat and bottom-hat transform with optimal structuring element: Application to retinal vessel segmentation," Lecture Notes in Computer Science (including subseries Lecture Notes in Artificial Intelligence and Lecture Notes in Bioinformatics), vol. 10317, pp. 533-540, 2017, doi: 10.1007/978-3-319-59876-5_59. 
[18] K. Ahmadi, A. Y. Javaid, and E. Salari, "Signal Processing: Image Communication An efficient compression scheme based on adaptive thresholding in wavelet domain using particle swarm optimization," Signal Processing : Image Communication, vol. 32, pp. 33-39, 2015, doi: 10.1016/j.image.2015.01.001.

[19] T. Y. Goh, S. N. Basah, H. Yazid, M. J. Aziz Safar, and F. S. Ahmad Saad, "Performance analysis of image thresholding: Otsu technique," Measurement: Journal of the International Measurement Confederation, vol. 114, no. June 2017, pp. 298307, 2018, doi: 10.1016/j.measurement.2017.09.052.

[20] N. Senthilkumaran and S. Vaithegi, "Image Segmentation By Using Thresholding Techniques For Medical Images," Computer Science \& Engineering: An International Journal, vol. 6, no. 1, pp. 1-13, 2016, doi: 10.5121/cseij.2016.6101.

[21] X. Ji, Y. Li, J. Cheng, and Y. Yu, "Cell Image Segmentation Based on an Improved Watershed Algorithm," International Congress on Image and Signal Processing (CISP 2015), vol. 1, pp. 433-437, 2015.

[22] A. Desiani, S. Yahdin, and A. Kartikasari, "Handling the imbalanced data with missing value elimination SMOTE in the classification of the relevance education background with graduates employment," IAES International Journal of Artificial Intelligence (IJ-AI), vol. 10, no. 2, pp. 346-354, 2021, doi: 10.11591/ijai. v10.i2.pp346-354. 